\title{
Effects of a novel cyclic RGD peptidomimetic on cell proliferation, migration and angiogenic activity in human endothelial cells
}

\author{
Vascular Cell 6:11 | DOI: 10.1186/2045-824X-6-11 | C Li et al.; licensee Publiverse Online S.R.L. 2014 \\ Received: 28 Oct 2013 | Accepted: 17 Oct 2014 | Published: 21 Oct 2014 \\ Fanelli Roberto $^{+}$, Schembri Laura ${ }^{+}$, Piarulli Umberto, Pinoli Monica, Rasini Emanuela, Paolillo Mayra ${ }^{@}$, \\ Galiazzo Marisa Carlotta ${ }^{@}$, Cosentino Marco ${ }^{@}$, Marino Franca@ \\ ${ }^{+}$Contributed equally ${ }^{@}$ Corresponding author
}

\begin{abstract}
Background

Cyclic RGD peptidomimetics containing a bifunctional diketopiperazine scaffold are a novel class of high-affinity ligands for the integrins $\alpha_{\mathrm{V}} \beta_{3}$ and $\alpha_{\mathrm{V}} \beta_{5}$. Since integrins are a promising target for the modulation of normal and pathological angiogenesis, the present study aimed at characterizing the ability of the RGD peptidomimetic cyclo [DKP-RGD] 1proliferation, migration and network formation in human umbilical vein endothelial cells (HUVEC).
\end{abstract}

\section{Methods}

Cell viability was assessed by flow cytometry and annexin V (ANX)/propidium iodide (PI) staining. Cell proliferation was evaluated by the ELISA measurement of bromodeoxyuridine (BrdU) incorporation. Network formation by HUVEC cultured in Matrigel-coated plates was evaluated by optical microscopy and image analysis. Integrin subunit mRNA expression was assessed by real time-PCR and Akt phosphorylation by western blot analysis.

\section{Results}

Cyclo [DKP-RGD] 1does not affect cell viability and proliferation either in resting conditions or in the presence of the pro-angiogenic growth factors VEGF, EGF, FGF, and IGF-I. Addition of cyclo [DKP-RGD] 1however significantly decreased network formation induced by pro-angiogenic growth factors or by IL-8. Cyclo [DKP-RGD] 1did not affect mRNA levels of $\alpha_{\mathrm{V}}, \beta_{3}$ or $\beta_{5}$ integrin subunits, however it significantly reduced the phosphorylation of Akt.

\section{Conclusions}

Cyclo [DKP-RGD] 1can be a potential modulator of angiogenesis induced by different growth factors, possibly devoid of the adverse effects of cytotoxic RGD peptidomimetic analogues.

\section{Keywords}

RGD peptidomimetics - Integrins - Angiogenesis - Human umbilical vein endothelial cells - Interleukin-8

\section{Introduction}

Angiogenesis, the growth of new blood vessels as sprouts or offshoots of the pre-existing microvasculature, is a physiological event occurring in the development of organisms, wound healing and the reproductive cycle, but it is also involved in pathologic processes such as inflammation, tumour growth and metastasis [ 1]. Angiogenesis can be stimulated by a large number of pro-angiogenic cytokines, such as vascular endothelial growth factor (VEGF), tumour necrosis factor $\alpha$ (TNF- $\alpha$ ), basic fibroblast growth factor (bFGF) and interleukin-8 (IL-8) [ 2, 3] .

Among the proteins involved in the angiogenic process, integrins play an important role by promoting endothelial cell attachment and migration on the surrounding extracellular matrix, cell to cell interaction and intracellular signal transduction [4]. Integrins are heterodimeric proteins composed of two non covalently associated $\alpha$ and $\beta$ 
transmembrane glycoproteins; $18 \alpha$ and $8 \beta$ subunits that give rise to 24 possible distinct integrin proteins [ 5,6$]$. Across their extracellular $\alpha / \beta$ subunit interface containing the metal ion-dependent adhesion site (MIDAS), integrins recognize and bind protein ligands through contiguous tripeptide sequences, the majority of which are present within flexible loop regions and contain an acidic residue [ 7]. Several integrins, including $\alpha_{\mathrm{V}}, \alpha_{5} \beta_{1}$ and $\alpha_{\text {IIb }} \beta_{3}$ integrins, recognize the Arg-Gly-Asp (RGD) sequence in endogenous ligands. The context of the ligand RGD sequence (flanking residues, three dimensional presentation) and individual features of the integrin binding pockets determine the recognition specificity and efficacy. These observations prompted many research groups to investigate the use of conformationally constrained cyclic RGD peptides and peptidomimetics as active and selective integrin ligands [ 8,9]. One of these, Cilengitide, namely cyclo-[Arg-Gly-Asp-D-Phe-N(Me)-Val] is currently in phase III clinical trials as an angiogenesis inhibitor for patients with glioblastoma multiforme alone [ 10] or in combination with other antiblastic drugs [ 11]. Recently, RGD compounds have been proposed also as targeting ligands for integrins in order to better characterize tumor neovascularisation [12]. Notwithstanding these results, the mechanism of RGD ligands in the inhibition of angiogenesis is not yet fully understood, as significant cross-talk exists in the regulation of angiogenesis between integrin operated pathways and, for instance, VEGF receptor pathways [13], and on these bases it has been proposed that agents able to inhibit multiple pathways would have important therapeutic potential [ 14].

Recently, some of us reported a new class of cyclic RGD peptidomimetics containing a bifunctional diketopiperazine (DKP) scaffold, showing a low nanomolar affinity for integrins $\alpha_{v} \beta_{3}$ and $\alpha_{v} \beta_{5}[15,16]$. The present study is aimed at characterizing the ability of the cyclic RGD peptidomimetic cyclo [DKP-RGD] 1(Figure 1) to affect cell viability, proliferation, migration and capillary network formation in human umbilical vein endothelial cells (HUVEC). In addition, the effect of cyclo [DKP-RGD] 1on mRNA expression of the integrin subunits $\alpha_{\mathrm{V}}, \beta_{3}$ and $\beta_{5}$, and on the phosphorylation of Akt, a serine/threonine-specific protein kinase that plays a key role in the regulation of vascular homeostasis and angiogenesis [17] was also investigated. Figure 1

Structure of the peptidomimetic cyclo [DKP-RGD] 1.

\section{Materials and methods}

\section{Reagents}

The peptidomimetic cyclo [DKP-RGD] 1was prepared according to a published procedure [ 16]. Annexin V-FITC Apoptosis Detection Kit I was purchased by Biosciences (BD, Italy). RNA extraction was performed using Quiazol reagent (Qiagen, Italy) and the quantitative real time RT-PCR reaction were performed using Quantitatec reverse transcription kit (Qiagen, Italy) and Quantitec sybr green pcr kit (Qiagen, Italy). The amount of proteins for western blot analysis were performed by the BCA protein Assay Kit (Pierce Protein Biology, Rockford, IL, USA). Anti-AKT and anti-pAKT, primary antibodies were purchased from Cell Signalling (Cell signalling, Italy) and horseradish peroxidase-conjugated goat anti-rabbit IgG secondary antibody for western blot were purchased from Upstate Biotechnology (Upstate Biotechnology, USA). The detection of the western blot membrane was performed by using ECL plus Western Blotting Detection System purchased from Amersham (Amersham, GE Healthcare Life Science, MI, Italy). Propidium iodide (PI) solution was purchased from Miltenyi (Miltenyi Biotec S.r.l., Bologna, Italy). Matrigel Basement Membrane Matrix $(10 \mathrm{mg} / \mathrm{ml})$ for the network formation assay was purchased from BD (Becton Dickinson Italy, Milan, Italy). Cell proliferation Biotrak Ver for the proliferation assay was purchased from GEhealthcare (GeHealthcare, Uppsala, Sweeden). Human umbilical vein endothelial cells (HUVEC) were obtained from PromoCell (PromoCell Gmbh, Germany). The EndoGRO ${ }^{\mathrm{TM}}$ VEGF Complete Media Kit composed of EndoGRO Basal Medium (SCME-BM) plus fetal bovine serum (FBS), L-glutamine, heparin sulphate, rh-VEGF, rh-EGF, rhFGF2, rh-IGF-I and ascorbic acid, and the MF-Membrane filters $(3.0 \mu \mathrm{m})$ for the cell migration assay were purchased from Millipore (Millipore S.p.A., MI, Italy). Recombinant Human CXCL8/IL-8 was purchased from R\&D (R\&D System, US, Europe).

\section{Cell cultures}

HUVEC were cultured in a medium supplemented with FBS $(2 \%)$, L-glutamine $(10 \mathrm{mM})$, heparin sulphate $(0.75$ $\mathrm{U} / \mathrm{ml}), \operatorname{VEGF}(5 \mathrm{ng} / \mathrm{ml}), \mathrm{EGF}(5 \mathrm{ng} / \mathrm{ml})$, FGF2 $(5 \mathrm{ng} / \mathrm{ml})$, IGF-I $(15 \mathrm{ng} / \mathrm{ml})$ and ascorbic acid $(50 \mu \mathrm{g} / \mathrm{ml})$ at $37^{\circ} \mathrm{C}$, in a moist atmosphere of $5 \% \mathrm{CO}_{2}$. HUVEC were used for the experiments between passage 2 and 8 . All the experiments were conducted under two different conditions: basal conditions (resting) i.e. cell cultured in EndoGRO basal medium alone, and stimulated conditions, i.e. with the addition of VEGF ( $5 \mathrm{ng} / \mathrm{ml})$, EGF $(5 \mathrm{ng} / \mathrm{ml})$, FGF2 (5 ng/ml), IGF-I $(15 \mathrm{ng} / \mathrm{ml})$ together with $10 \%$ FBS. In viability, proliferation and migration assays, cells were used after overnight culture in EndoGRO basal medium alone (starvation).

\section{Cell viability}

Cell viability assay was performed by flow cytometry. Briefly, after treatment HUVEC were detached with a trypsin solution, centrifuged at $600 \mathrm{~g}$ for $5 \mathrm{~min}$ at room temperature and the supernatant was finally removed. The cell pellet was resuspended in $100 \mu \mathrm{L}$ Binding Buffer $1 \times$ with the addition of $5 \mu \mathrm{L}$ annexin V (ANX)-FITC and $5 \mu \mathrm{L}$ PI, and finally incubated for $15 \mathrm{~min}$ at room temperature in the dark. Samples were stored on ice and analyzed without washing. Acquisition was performed on a BD FACSCanto II flow cytometer (Becton Dickinson Italy, Milan, Italy) and data were analyzed using BD FACSDiva software (version 6.1.3). HUVEC were identified on the basis of forward- 
scatter (FSC) and side-scatter (SSC) properties, and a minimum of 15000 cells for each sample was collected in the gate. Viable, apoptotic and necrotic HUVEC were identified on a biparametric plot ANX-FITC vs PI. Data were finally expressed as\% viable (ANX-/PI-), early apoptotic cells (ANX+/PI-), late apoptotic/necrotic cells (ANX+/PI+) and necrotic cells (ANX-/PI+).

\section{Proliferation assay}

To assess HUVEC proliferation, $1 \times 10^{4}$ cells were seeded in duplicate in a 96-well plate and cultured for $24 \mathrm{~h}$ without or with cyclo [DKP-RGD] 1at different concentrations. Proliferation was then measured by a colorimetric immunoassay, based on the ELISA measurement of bromodeoxyuridine (BrdU) incorporation during DNA synthesis. The absorbance (ABS) of the samples was determined by means of a spectrophotometer (Model 680, Bio-Rad Laboratories, Hercules, CA, USA) with wavelength set at $450 \mathrm{~nm}$, and finally expressed as the difference between BrdU positive and negative samples, expressed as Optical Density (O.D.).

\section{Cell migration assay}

Cell migration was measured by means of a Boyden chamber assay. Briefly, $1 \times 10^{5}$ HUVEC were seeded in the top well of the Boyden chamber, cyclo [DKP-RGD] 1 was added in the bottom or in the top compartment, and a $3 \mu \mathrm{m}$-pore cellulose nitrate filter was placed between the two compartments. Stimulated migration was assessed by putting VEGF, EGF, IGF-I, and FGF2 in the bottom chamber. After an incubation period of $5 \mathrm{~h}$ at $37^{\circ} \mathrm{C}$, the filter was recovered, dehydrated, fixed, and finally stained with hematoxylin. Migration into the filter was quantified by measuring the distance (in $\mu \mathrm{m}$ ) from the surface of the filter to the leading front of cells using an optical microscope (Axiolab, Carl Zeiss S.p.A. Milan, Italy).

\section{Angiogenesis assay}

To assess angiogenic activity, HUVEC $2.5 \times 10^{4}$ cells were seeded in a 24 -well plate coated with $100 \mu \mathrm{l} /$ well of Matrigel previously polymerized for $1 \mathrm{~h}$ at $37^{\circ} \mathrm{C}$. Cells were then incubated for $5 \mathrm{~h}$ at $37^{\circ} \mathrm{C}$ in a moist atmosphere of $5 \% \mathrm{CO}_{2}$ without or with cyclo [DKP-RGD] 1under either resting or stimulated conditions. In some experiments IL-8 $(10 \mathrm{nM})$ was used as pro-angiogenic stimulus. Network formation was evaluated by phase-contrast microscopy using a fluorescence microscope (Axiovert 40CFL, Carl Zeiss S.p.A. Milan, Italy). Network formation was finally quantified in terms of mean number of loops per field as topological parameters and the total length of the branches. For the purpose of the analysis, loops were defined as any complete ring formed by HUVEC, while open ramifications were considered as branches. The total branch length (pixels) and the number of loops were quantified using the ImageJ image analysis software ( http://rsbweb.nih.gov/ij/).

\section{Real time PCR}

Cells were treated for $5 \mathrm{~h}$ in the presence or absence of $1 \mu \mathrm{M}$ cyclo[DKP-RGD] 1 in different growth conditions, as previously described. At the end of the treatment, RNA extraction was performed using the Qiazol lysis reagent. Primers were designed by using the "Primer3 input" software ( http://frodo.wi.mit.edu/cgi-

bin/primer3/primer3.cgi/primer3_www.cgi) and the specificity of each primer was controlled by the BLAST software ( http://blast.ncbi.nlm.nih.gov) (Table 1). Real time PCR was performed as previously reported [ 18] At the end of the reaction, a melting curve analysis was carried out to check for the presence of primer-dimers. Comparison of the expression of each gene was determined by using GAPDH as housekeeping gene. Each run was analyzed in duplicate and data are finally expressed as $2^{-\Delta \mathrm{ct}}$.

\section{Table 1}

\begin{tabular}{|c|c|c|c|}
\hline Gene & Ref. sequence & Sequence & Product size \\
\hline$\alpha_{\mathrm{v}}$ & NM_002210 & $\begin{array}{l}\text { Forward: actggcttaagagagggctgtg } \\
\text { Reverse: tgccttacaaaaatcgctga }\end{array}$ & 110 \\
\hline$\beta_{3}$ & NM_000212 & $\begin{array}{l}\text { Forward: agacactcccacttggcatc } \\
\text { Reverse: tcctcaggaaaggtccaatg }\end{array}$ & 123 \\
\hline$\beta_{5}$ & NM_002213 & $\begin{array}{l}\text { Forward: agcctatctccacgcacact } \\
\text { Reverse: cctcggagaaggaaacatca }\end{array}$ & 91 \\
\hline GAPDH & NM_001289746.1 & $\begin{array}{l}\text { Forward: caactgtgaggaggggagatt } \\
\text { Reverse: cagcaagagcacaagaggaag }\end{array}$ & 97 \\
\hline
\end{tabular}

Sequences of the primers and PCR products size

\section{Western blot analysis}

Cells grown in 60-mm dishes were treated for $5 \mathrm{~h}$ with $1 \mu \mathrm{M}$ cyclo [DKP-RGD] 1 . The cells were then rinsed twice in ice-cold PBS and $200 \mu \mathrm{l}$ of the cell lysis buffer (composition: $50 \mathrm{mM}$ Tris- $-\mathrm{HCl} \mathrm{pH} \mathrm{7.4,1 \%} \mathrm{v/v} \mathrm{NP40,0.25 \%} \mathrm{w/v}$ sodium deoxycholate, $1 \mathrm{mM}$ phenylmethylsulphonyl-fluoride, $1 \mathrm{mM}$ Na3VO4, $1 \mathrm{mM}$ EDTA, $30 \mathrm{mM}$ sodium pyrophosphate, $1 \mathrm{mM} \mathrm{NaF}, 1 \mathrm{mg} / \mathrm{ml}$ leupeptin, $1 \mathrm{mg} / \mathrm{ml}$ pepstatin A, $1 \mathrm{mg} / \mathrm{ml}$ aprotinin and $1 \mathrm{mg} / \mathrm{ml} \mathrm{microcystin)} \mathrm{was}$ 
added to the dishes. After scraping, cells were sonicated for $10 \mathrm{~s}$, centrifuged at $12000 \mathrm{~g}$ for $5 \mathrm{~min}$ at $4^{\circ} \mathrm{C}$ and the amount of proteins in the supernatant was measured using the BCA protein assay. For western blot analysis, $20 \mu \mathrm{g}$ of proteins were separated by $10 \%$ SDS-PAGE at $150 \mathrm{~V}$ for $2 \mathrm{~h}$ and blotted onto $0.22 \mathrm{~mm}$ nitrocellulose membranes at $90 \mathrm{~mA}$ for $16 \mathrm{~h}$. The membranes were first blocked for $2 \mathrm{~h}$ in TRIS buffered saline solution (TBST, composition: TRIS $10 \mathrm{mM}, \mathrm{NaCl} 150 \mathrm{mM}, 0.1 \%$ Tween 20) plus 5\% low fat dry milk (TBSTM) and then incubated with the appropriate antibody diluted 1:1000 in TBSTM, for $16 \mathrm{~h}$ at $4^{\circ} \mathrm{C}$ under gentle agitation. The membranes were rinsed three times in TBST and then incubated for $2 \mathrm{~h}$ at $21^{\circ} \mathrm{C}$ with the secondary antibody diluted 1:10000 in TBSTM. Membranes were then rinsed three times in TBST and luminescence was detected by using the appropriate kit, and densitometric analysis was performed as previously reported [18].

\section{Statistical analysis}

Data are shown as means \pm standard deviation (SD) unless otherwise indicated. Statistical significance of the differences was assessed by two-tailed Student's $t$ test for paired data or by One-way analysis of variance followed by Dunnett's Multiple Comparison Test as appropriate. Calculations were performed using a commercial software (GraphPad Prism version 5.00 for Windows, GraphPad Software, San Diego California USA, http://www.graphpad.com).

\section{Results}

\section{Viability and apoptosis}

Viable cells, measured after $24 \mathrm{~h}$, were $81.7 \pm 6.0 \%$ in basal conditions and $90.2 \pm 3.7 \%$ in the presence of VEGF, EGF, IGF-I, and FGF2 ( $\mathrm{n}=4, \mathrm{P}=0.066$ s basal conditions). Early apoptotic cells were, respectively, $10.8 \pm 2.0 \%$ and $6.5 \pm$ $3.4 \%(\mathrm{n}=4, \mathrm{P}=0.117)$, late apoptotic/necrotic cells were $5.4 \pm 3.5 \%$ and $1.7 \pm 0.3 \%(\mathrm{n}=4, \mathrm{P}=0.082)$ and necrotic cells were $2.5 \pm 1.5 \%$ and $1.6 \pm 0.8 \%(\mathrm{n}=4, \mathrm{P}=0.430)$. The presence of cyclo[DKP-RGD] 1 in the $1 \times 10^{-12}-1 \times 10^{-6} \mathrm{M}$ did not affect the percentage of viable, early apoptotic, late apoptotic/necrotic or necrotic cells to any significant extent in either experimental conditions (with cyclo[DKP-RGD] $11 \times 10^{-6} \mathrm{M}$, viable cells: $85.4 \pm 3.4 \%$ and $86.8 \pm 9.2 \%$; early apoptotic cells: $10.5 \pm 3.1 \%$ and $9.1 \pm 7.7 \%$; late apoptotic/necrotic cells: $2.7 \pm 0.6 \%$ and $2.4 \pm 0.9 \%$; necrotic cells: 1.8 $\pm 0.8 \%$ and $1.9 \pm 1.1 \%$; in all the cases, $\mathrm{n}=4$ and $\mathrm{P}>0.05$ vs control).

\section{Proliferation}

HUVEC proliferation in basal conditions was $0.25 \pm 0.18$ O.D. and increased up to $1.85 \pm 0.50$ O.D. in the presence of VEGF, EGF, IGF-I, and FGF2 ( $\mathrm{n}=3-6, P<0.05)$. Cell incubation with cyclo [DKP-RGD] 1 up to $1 \times 10^{-5} \mathrm{M}$ did not significantly affect either basal or stimulated proliferation (data not shown).

\section{Migration}

Spontaneous migration of HUVEC was $25.2 \pm 9.5 \mu \mathrm{m}$ and increased by $87.8 \pm 53.7 \%$, up to $44.9 \pm 13.4 \mu \mathrm{m}$ in the presence of VEGF, EGF, IGF-I, and FGF2 in the bottom chamber ( $\mathrm{n}=17, P<0.001 \mathrm{vs}$ basal conditions). When cyclo [DKP-RGD] 1was added in the top chamber, i.e. together with HUVEC, spontaneous migration was increased and stimulated migration was decreased, while when it was added in the bottom chamber both spontaneous and stimulated migration were increased (Figure 2).

\section{Figure 2}


basal conditions

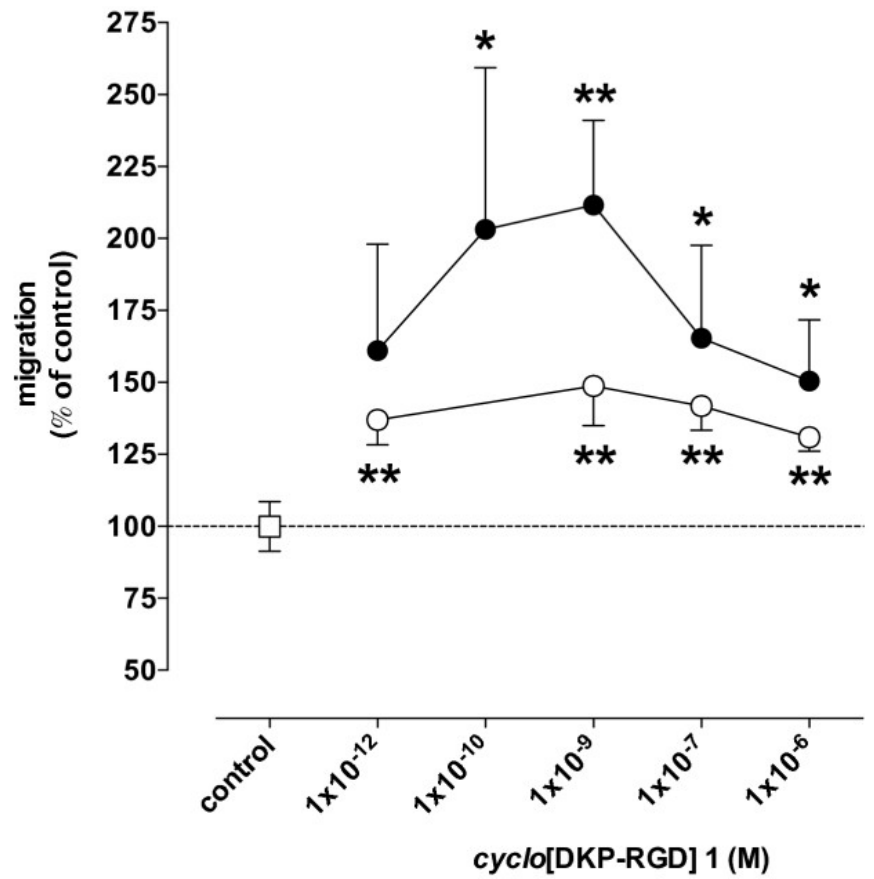

VEGF + EGF + IGF-I + FGF2
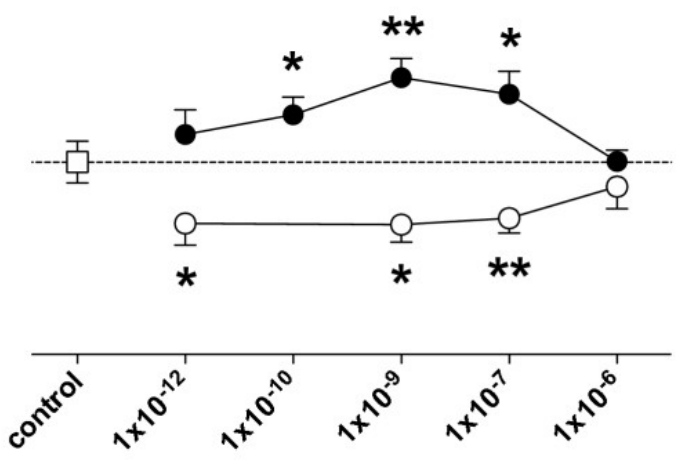

cyclo[DKP-RGD] 1 (M)

Effect of cyclo [DKP-RGD] 1 on HUVEC migration in the Boyden chamber assay.Cells were placed in the top compartment. Empty circles: cyclo [DKP-RGD] 1placed in the top compartment. Filled circles: cyclo [DKP-RGD] 1placed in the bottom compartment. Data are means \pm SEM of 5-17 separate experiments. $*=\mathrm{P}<0.05$ and $* *=\mathrm{P}<$ 0.01 vs respective control.

\section{Angiogenesis}

HUVEC under basal conditions did not show any significant network formation. Addition of VEGF, EGF, IGF-I, and FGF2 induced a significant network formation, which was even higher when cells were treated with IL-8 (Figure 3 ).

\section{Figure 3}



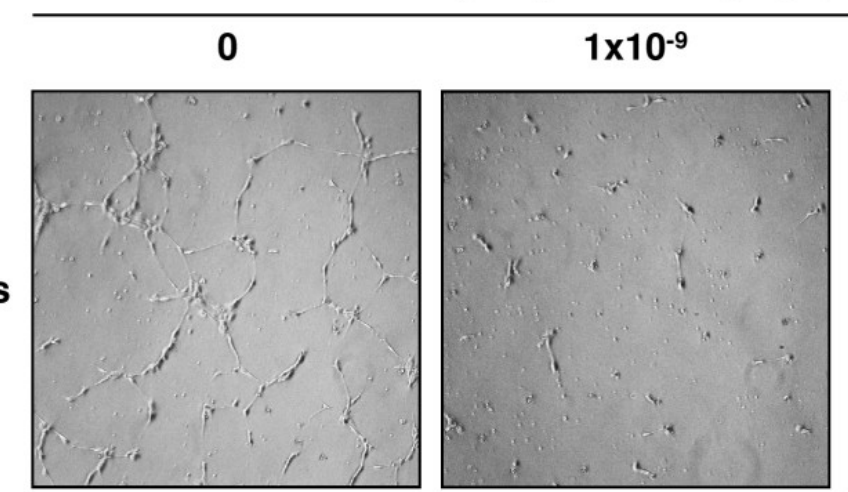

$1 \times 10^{-6}$

\section{basal conditions}
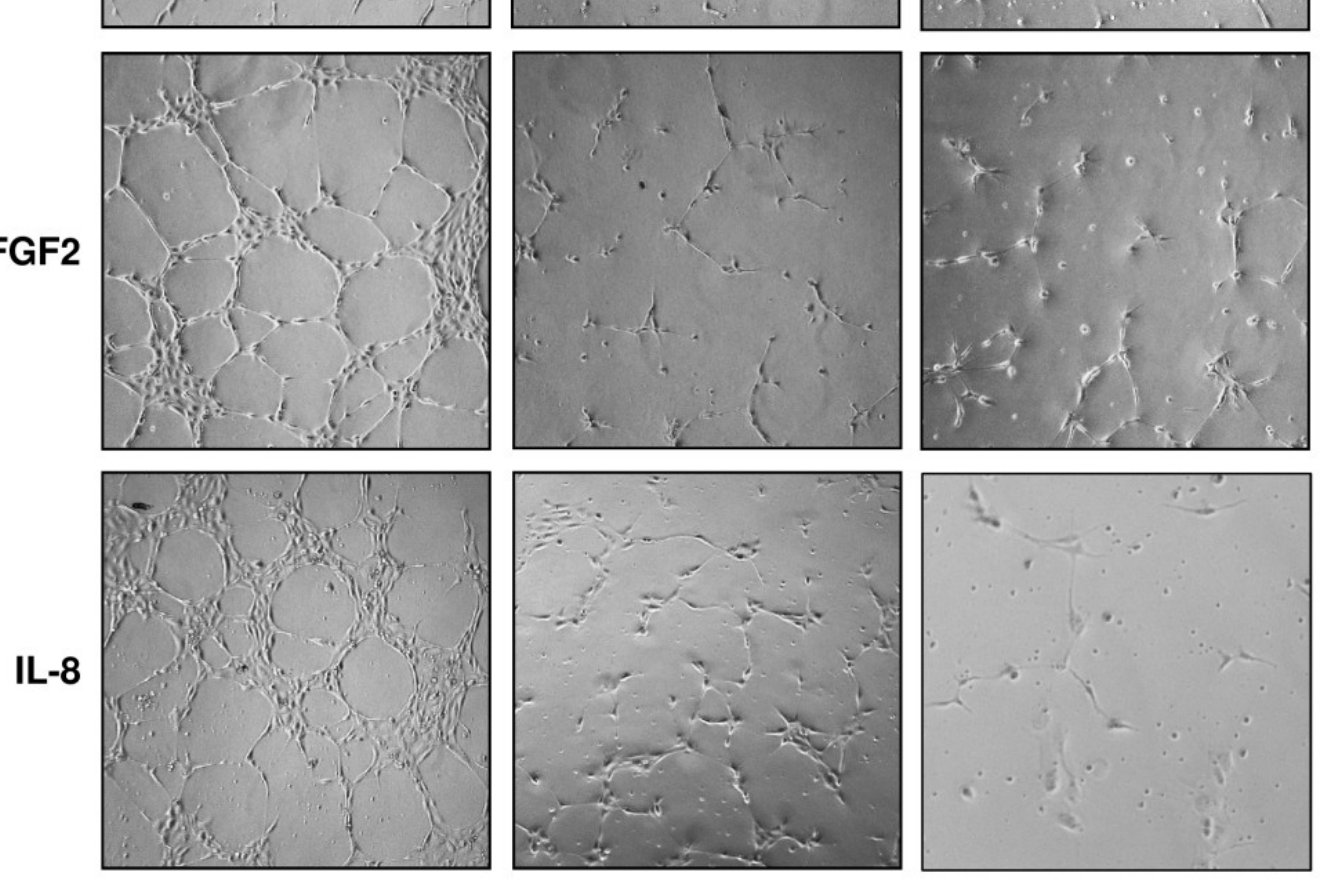

Representative phase contrast photomicrographs of HUVEC plated on Matrigel in basal conditions or in the presence of VEGF, EGF, IGF-I, and FGF2 or IL-8, without and with cyclo [DKP-RGD] 1 at different concentrations.

Coincubation with cyclo [DKP-RGD] 1did not significantly affect angiogenesis of HUVEC under basal conditions (Figure $3 \mathrm{~b}$-d), however it significantly and profoundly decreased the effect of VEGF, EGF, IGF-I, and FGF2 (Figure 3 and Figure 4, panel A) as well as the effect of IL-8 (Figure 3 and Figure 4, panel B).

\section{Figure 4}




\section{VEGF + EGF + IGF-I + FGF2}

A

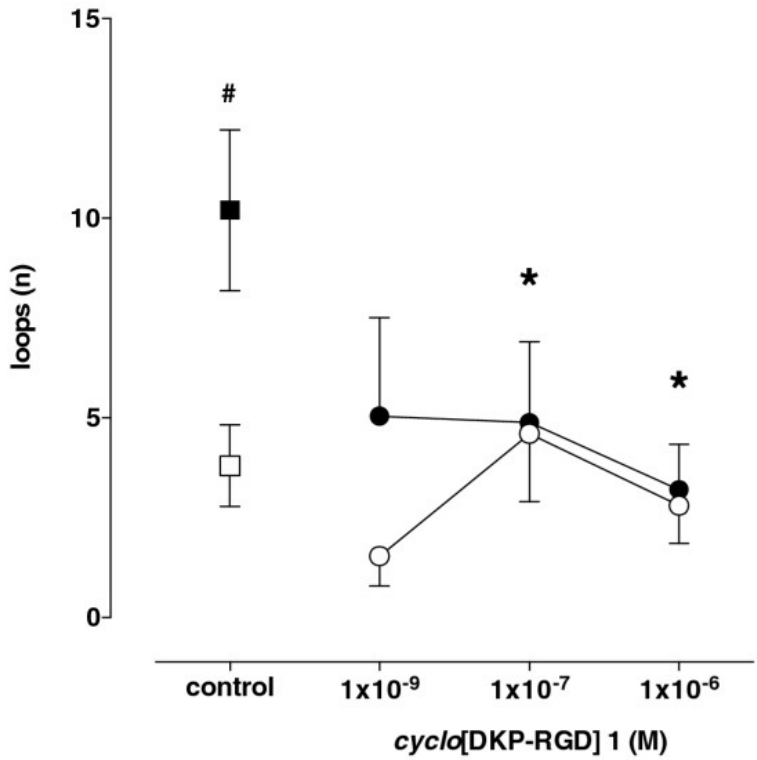

B

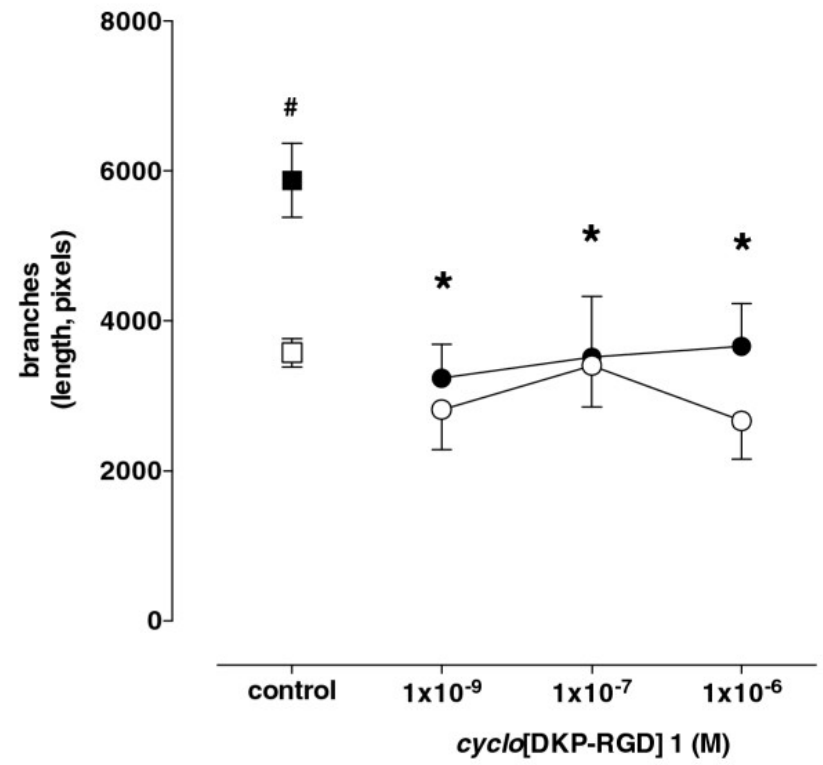

IL-8
A

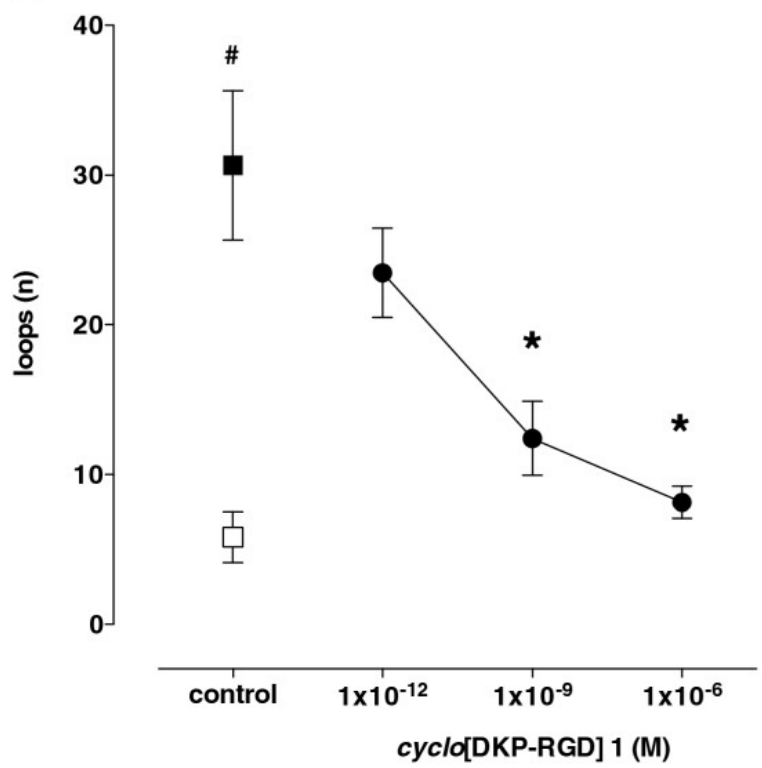

B

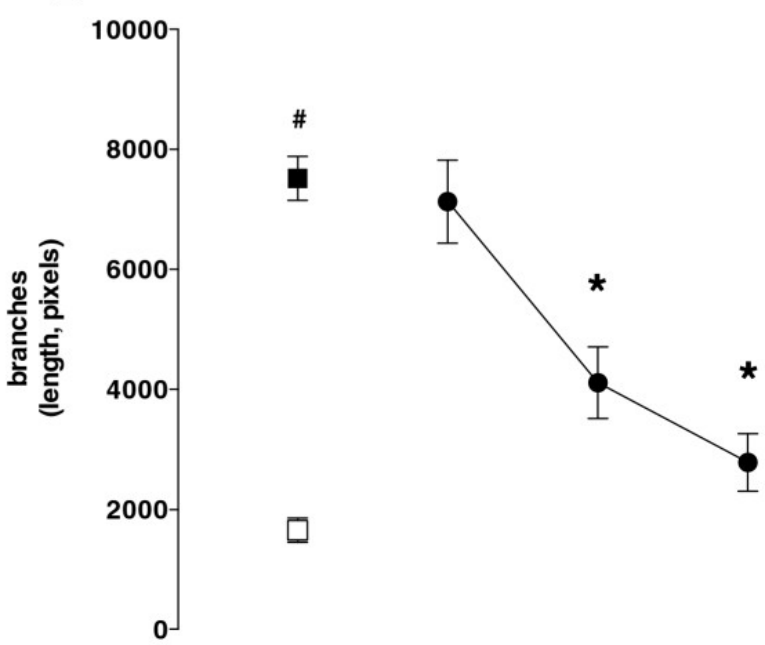

control

cyclo[DKP-RGD] 1 (M)

Effect of cyclo [DKP-RGD] 1 on HUVEC angiogenesis induced by VEGF, EGF, IGF-I, and FGF2 (upper panels) or IL-8 (lower panels).Angiogenesis was evaluated as both number of loops (A)and length of branches (B). Empty symbols: basal conditions; filled symbols: stimulated conditions. Data are means \pm SEM of $3-5$ separate experiments. $\#=\mathrm{P}<0.01$ vs basal conditions, $*=\mathrm{P}<0.01$ vs respective control.

\section{Expression of mRNA for $\alpha_{\mathrm{v}}, \beta_{3}$ and $\beta$ sintegrin subunits}

HUVEC expressed comparable amounts of the mRNA for $\alpha_{\mathrm{v}}, \beta_{3}$ and $\beta_{5}$ integrin subunits in both basal conditions and after treatment with VEGF, EGF, IGF-I, and FGF2, and coincubation with $1 \times 10^{-6} \mathrm{M}$ cyclo [DKP-RGD] 1did not affect mRNA expression of any of the subunits in either experimental conditions (Table 2).

Table 2

\begin{tabular}{|c|c|c|c|c|}
\hline \multirow[t]{2}{*}{ Subunit } & \multirow{2}{*}{$\begin{array}{c}\text { control } \\
2^{-\Delta c t} \times 10^{2}\end{array}$} & \multicolumn{3}{|c|}{ + cyclo [DKP-RGD] 1} \\
\hline & & $2^{-4 c t} \times 10^{2}$ & Ratio vs Control & P vs Control \\
\hline \multicolumn{5}{|c|}{ A.Basal conditions } \\
\hline$\alpha_{\mathrm{v}}$ & $6.65 \pm 6.41$ & $6.59 \pm 5.24$ & $1.32 \pm 0.57$ & 0.944 \\
\hline$\beta_{3}$ & $0.89 \pm 0.87$ & $0.91 \pm 0.76$ & $1.08 \pm 0.27$ & 0.928 \\
\hline
\end{tabular}




\begin{tabular}{|c|c|c|c|c|}
\hline \multirow[t]{2}{*}{ Subunit } & control & \multicolumn{3}{|c|}{ + cyclo [DKP-RGD] 1} \\
\hline & $\times 10$ & $\times 10$ & Ratio vs Control & $P$ vs Control \\
\hline$\beta_{5}$ & $1.36 \pm 1.18$ & $1.52 \pm 1.34$ & $1.08 \pm 0.07$ & 0.225 \\
\hline \multicolumn{5}{|c|}{ B.With VEGF, EGF, IGF, and FGF } \\
\hline$\alpha_{\mathrm{v}}$ & $13.31 \pm 12.80$ & $15.09 \pm 10.66$ & $1.28 \pm 0.42$ & 0.494 \\
\hline$\beta_{3}$ & $1.15 \pm 1.07$ & $1.41 \pm 1.07$ & $1.43 \pm 0.35$ & 0.288 \\
\hline$\beta_{5}$ & $1.23 \pm 1.25$ & $1.31 \pm 1.13$ & $1.34 \pm 0.46$ & 0.461 \\
\hline
\end{tabular}

Data are means $\pm \mathrm{SD}$ of 3 separate experiments.

Real time PCR analysis of the expression of mRNA for the integrin subunits $\alpha_{\mathrm{v}}, \beta_{3}$ and $\beta_{5}$ in HUVEC cultured for $5 \mathrm{~h}$ in basal conditions and with VEGF, EGF, IGF, and FGF, alone (control) or in the presence of $1 \mu \mathrm{M}$ cyclo [DKP-RGD] 1

\section{Akt phosphorylation}

Treatment of HUVEC with $1 \times 10^{-6} \mathrm{M}$ cyclo [DKP-RGD] 1in basal conditions reduced phosphorylated Akt, from $16241.7 \pm 1763.3$ to $8702.7 \pm 2008.7$ optical density arbitrary units, down to $53.2 \pm 7.9 \%$ of control $(n=3, P=0.001)$, without however any significant effect in the presence of VEGF, EGF, IGF-I, and FGF2 (15406.0 \pm 1218.8 to 15174.7 \pm 663.9 optical density arbitrary units, $\mathrm{n}=3, \mathrm{P}=0.735$ ) (Figure 5 ).

Figure 5

\section{basal conditions}

C

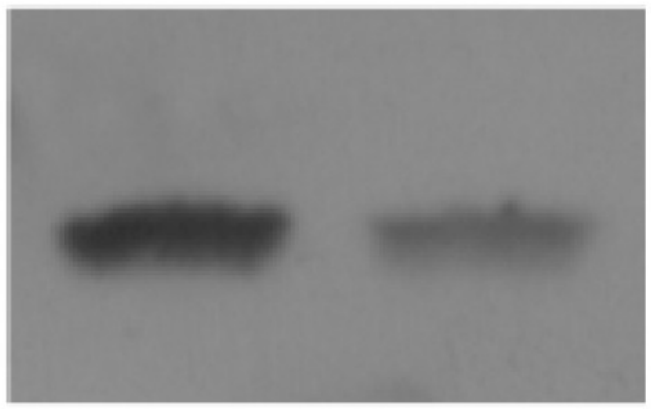

\section{VEGF + EGF + IGF-I + FGF2}

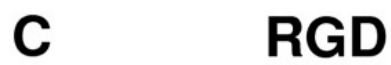

pAkt

Akt
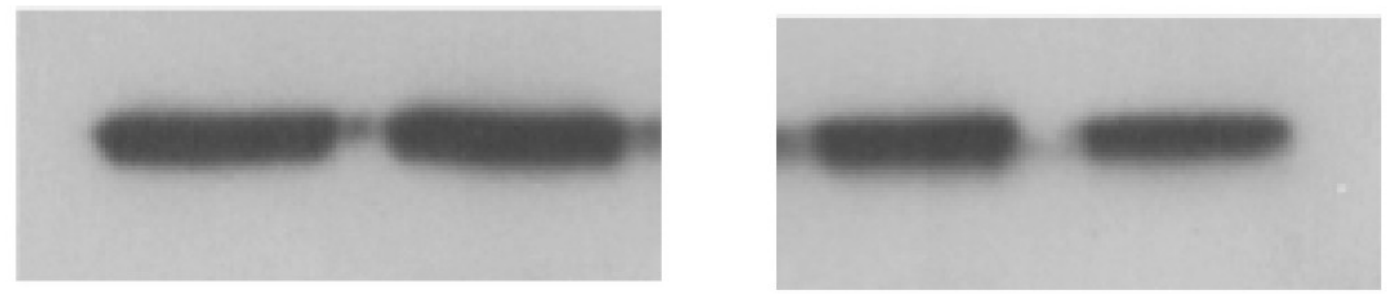

Western blot analysis of Akt phosphorylation in HUVEC cultured for $5 \mathrm{~h}$ in basal conditions and with VEGF, EGF, IGF-I, and FGF2, alone (control, C) or in the presence of $1 \mu \mathrm{M}$ cyclo [DKP-RGD] 1 (RGD).Data are from one representative of 3 separate experiments.

\section{Discussion}

HUVEC represent a valid in vitro model which provides seminal insights into the cellular and molecular events leading to neovascularization in response to inflammation and hypoxia in cancer, ischemic events, and in embryogenesis [19]. As anticipated in the introduction, integrins are key actors in angiogenesis and vascular homeostasis, acting as promoters of endothelial cell-matrix interactions [20]. It has been recognized that pharmacological inhibition of the $\alpha_{\mathrm{v}} \beta_{3}$ subtype suppresses angiogenesis in many experimental models and $\alpha_{\mathrm{v}} \beta$ 3 antagonists (i.e. antibodies, peptides and peptidomimetics) are being developed as antiangiogenic drugs [ 21]. It is known that integrins $\alpha_{v} \beta_{3}$ and $\alpha_{v} \beta_{5}$ are expressed on HUVEC [22]; as a consequence these cells represent a suitable model to study the effects of agents acting on such targets. In the present study we used HUVEC to test the ability of the peptidomimetic integrin ligand cyclo [DKP-RGD] 1to affect the key steps of the angiogenic process by evaluating its effects on proliferation, migration and capillary-like network formation. Some of us previously showed that $c y c l o$ 
[DKP-RGD] linhibits vitronectin binding to $\alpha_{v} \beta_{3}$ and $\alpha_{v} \beta$ sintegrins with IC ${ }_{50}$ of $4.5 \pm 1.1 \mathrm{nM}$ and $149 \pm 25 \mathrm{nM}$ respectively [16].

In our experiments, the effects of cyclo [DKP-RGD] 1on HUVEC activity were tested in resting conditions as well as in the presence of a culture medium enriched with growth factors known to promote angiogenesis such as VEGF, EGF, IGF-I and FGF2 or after addition of the pro-inflammatory chemokine IL-8, which has a key role in the regulation of pathological angiogenesis [ 2,3]. According to our results, cyclo [DKP-RGD] 1is indeed able to strongly inhibit angiogenesis, as indicated by the reduction of network formation (vide infra), and this occurs without affecting cell viability, apoptosis or proliferation. Most anti-angiogenic compounds acting through the inhibition of integrin function, such as cilengitide, exhibit cytotoxic activity in the same or very close concentration range [23]. In our experimental conditions, our compound did not affect cell viability and apoptosis or cell proliferation, suggesting that its antiangiogenic activity is likely independent from cytotoxicity. This latter observation deserves further consideration because angiogenesis represents a key step in some pathological conditions beyond tumour growth. For example atheromatous plaque vulnerability is closely related to neoangiogenesis [24]; in this latter case a cytotoxic effect exerted by an antiangiogenic compound could represent a risk for adverse effects. On the other hand, the lack of cytotoxic effects by cyclo [DKP-RGD] 1was also observed in several different cell-lines such as ovarian carcinoma IGROV-1 or SKOV3, human pancreatic carcinoma PANC-1 and MIA-PaCa2, human osteosarcoma U2-OS [ 25], and can be considered therefore as a general feature of our compound. Whether this lack of cytotoxicity might be suggestive of reduced toxicity and increased tolerability in vivo in different pathological conditions needs to be assessed in specific studies.

Investigation of the specific mechanisms responsible for the antiangiogenic effects of cyclo [DKP-RGD] 1was beyond the purpose of the present study; nonetheless, according to our results, this compound did not affect the mRNA levels for the integrin subunits $\alpha_{v}, \beta_{3}$ and $\beta_{5}$, which are the main targets of its action, but it effectively inhibited the phosphorylation of Akt, a serine/threonine-specific protein kinase that plays a key role in the regulation of vascular homeostasis and angiogenesis [ 17]. The fact that the inhibition of Akt phosphorylation is only detected under basal conditions may be explained considering that, in the presence of growth factors converging on the same intracellular signalling pathway, the inhibitory effect exerted by cyclo [DKP-RGD] 1is probably overcome. Inhibition of Akt phosphorylation by cyclo [DKP-RGD] 1 is likely the results of disruption of proper endothelial cell-extracellular matrix attachment, due to integrin engagement by cyclo [DKP-RGD] 1. Indeed, it has already been reported that antagonists against $\alpha_{\mathrm{v}} \beta_{3}$ or $\alpha_{\mathrm{v}} \beta_{5}$ integrin interfere with angiogenesis induced by several growth factors: for instance, $\alpha_{v} \beta_{3}$ integrin associates with VEGF and platelet-derived growth factor (PDGF) receptors and potentiates VEGF or PDGF signaling, respectively [ 26].

Disruption of integrin functions may possibly explain also the effects of cyclo [DKP-RGD] 1on HUVEC migration. Indeed, in the presence of cyclo [DKP-RGD] 1migration was increased in resting conditions but it was decreased in stimulated conditions when the compound was added in the top compartment of the Boyden chamber, together with the cells, while it was increased in both resting and stimulated conditions when the compound was added in the bottom compartment. As a temptative explanation, we propose that increased migration results from the direct inhibitory effect of cyclo [DKP-RGD] 1on integrins $\alpha_{\mathrm{v}} \beta_{3}$ and $\alpha_{\mathrm{v}} \beta_{5}$, resulting in reduced cell anchorage to surfaces. On the other side, the slight decrease of stimulated migration and the reduced increase of spontaneous migration when cyclo [DKP-RGD] 1 was added in the same compartment in which the cells were placed might imply also a slight chemoattractant effect of this compound, which would therefore not only increase cell random migration through decreased integrin-mediated attachment to the surfaces, but also attract the cells along its concentration gradient. The in vivo relevance of such effect, where no concentration gradient is expected to occur, is however questionable. Remarkably, the effect exerted by cyclo [DKP-RGD] 1 was apparently bell-shaped, with a peak at about $1 \times 10^{-9} \mathrm{M}$ (which however was not observed in the angiogenesis assay). Whether this finding implies different modes of action depending on the extension of integrin engagement on the cell surface, it should be established in specific experiments. Disruption of integrin function could therefore explain both the increased migration and the anti-angiogenic activity exerted by cyclo [DKPRGD] 1. A similar effect was observed by Mrksich and co-workers [27], who promoted cell migration on selfassembled monolayers containing immobilized cyclic RGD by addition of exogenous linear RGD ligands [ 27].

In our experiments, cyclo [DKP-RGD] 1effectively inhibited angiogenesis induced by the growth factors VEGF, EGF, IGF-I and FGF2, as well as by IL-8. All these proangiogenic agents act through distinct membrane receptors [ 28, 29] which result in the activation of extensively overlapping intracellular cascades finally activating common effector molecules, such as NF- $x$ B or HIF-1 [28]. In addition, recent evidences indicate that direct interactions may occur between integrin activated pathways and signalling from VEGF receptors [ 30] and EGF receptors [ 31]. Collectively, in the light of such observations, our results support the ability of cyclo [DKP-RGD] 1to block common mechanisms, resulting in the effective inhibition of angiogenesis triggered by multiple agents. Angiogenesis is a process that occurs not only in cancer, but also in many other critical diseases such as atherosclerosis [ 32], and the relevance of cyclo [DKP-RGD] 1-induced effects in such conditions needs careful assessment.

In conclusion, the data of the present study show that the novel compound cyclo [DKP-RGD] 1, an $\alpha_{\mathrm{v}} \beta_{3}$ and $\alpha_{\mathrm{v}} \beta$ sintegrin ligand, effectively inhibits angiogenic processes in HUVEC, possibly through mechanisms involving reduced Akt phosphorylation and disruption of integrin-mediated adhesion, without affecting their viability and proliferation. We propose therefore this compound as a candidate modulator of angiogenesis occurring in different conditions, possibly devoid of the adverse effects of cytotoxic analogues. Further studies clarifying the in vivo activity of cyclo [DKP-RGD] 1, including a complete toxicological assessment, as well as a thorough investigation of the intracellular pathways involved its effects are currently underway in order to evaluate its possible potential applications as a novel pharmacotherapeutic compound. 


\section{Declarations}

\section{Acknowledgements}

This study was supported by a grant from Fondazione CARIPLO (Project RE-D DRUG TRAI-N 2010-1373:

Multidisciplinary approaches in research and development of innovative drugs: project for an international collaborative training network) to UP and MC. RF and LS gratefully acknowledge Regione Lombardia (Project RE-D DRUG TRAI-N) for two-year fellowship grants. We also gratef ully acknowledge Ministero dell'Università e della Ricerca for financial support (PRIN project 2010NRREPL: Synthesis and biomedical applications of tumor-targeting peptidomimetics). The valuable collaboration of Angela Scanzano (PhD Course in Clinical and Experimental Pharmacology, Center for Research in Medical Pharmacology, University of Insubria) is gratefully acknowledged.

\section{Authors' original submitted files for images}

Below are the links to the authors' original submitted files for images.

Authors' original file for figure 1

Authors' original file for figure 2

Authors' original file for figure 3

Authors' original file for figure 4

Authors' original file for figure 5

Roberto Fanelli, Laura Schembri contributed equally to this work.

\section{Competing interests}

The authors declare that they have no competing interests.

\section{Authors' contributions}

$\mathrm{RF}$ and $\mathrm{LS}=$ study design, performing all in vitro experiments and data handling. $\mathrm{UP}=$ Study design and manuscript preparation $\mathrm{MP}=$ in vitro experiments on morphogenesis and data handling. $\mathrm{ER}=$ flow cytometry analysis and data handling $\cdot \mathrm{MP}$ and $\mathrm{MCG}=$ real time PCR and Western Blot experiments and data handling $\cdot \mathrm{MC}=$ Study design, data handling, manuscript preparation and revision $\cdot \mathrm{FM}=$ Study design, data handling, manuscript preparation and revision.

\section{References}

1. Carmeliet P. Mechanisms of angiogenesis and arteriogenesis. Nat Med. 2000;6:389-395.

View Article Google Scholar

2. D’Andrea LD, Del Gatto A, Pedone C, Benedetti E. Peptide-based molecules in angiogenesis. Chem Biol Drug Des. 2006;67:115-126.

View Article Google Scholar

3. Li A, Dubey S, Varney ML, Bhavana J. IL-8 Directly enhanced endothelial cell survival, proliferation, and matrix metalloproteinases production and regulated angiogenesis. J Immunol. 2003;170:3369-3376. View Article Google Scholar

4. Juliano RL. Signal transduction by cell adhesion receptor and the cytoskeleton: function of integrins, cadherins, selectins, and immunoglobulin-superfamily members. Annu Rev Pharmacol Toxicol. 2002;42:283-323.

View Article Google Scholar

5. Hodivala-Dilke KM, Reynolds AR, Reynolds LE. Integrins in angiogenesis: multitalented molecules in a balancing act. Cell Tissue Res. 2003;314:131-144.

View Article Google Scholar

6. Plow EF, Haas TA, Zhang L, Loftus J, Smith JW. Ligand binding to integrins. J Biol Chem. 2000;275:2178521788.

View Article Google Scholar 
7. Xiong JP, Stehle T, Zhang R, Joachimiak A, Frech M, Goodman SL, Arnaout MA. Crystal structure of the extracellular segment of integrin alpha V beta 3 in complex with an Arg-Gly-Asp ligand. Science. 2002;296:151-155.

View Article Google Scholar

8. Paolillo M, Russo MA, Serra M, Colombo L, Schinelli S. Small molecule integrin antagonists in cancer therapy. Mini-Rev Med Chem. 2009;9:1439-1446.

View Article Google Scholar

9. Schottelius M, Laufer B, Kessler H, Wester HJ. Ligands for mapping alphavbeta3-integrin expression in vivo. Acc Chem Res. 2009;42:969-980.

View Article Google Scholar

10. Mas-Moruno C, Rechenmacher F, Kessler H. Cilengitide: the first anti-angiogenic small molecule drug candidate. Design, synthesis and clinical evaluation. Anti-Cancer Agents Med Chem. 2010;10:753-768. View Article Google Scholar

11. Kim YH, Lee JK, Kim B, DeWitt JP, Lee JE, Han JH, Kim SK, Oh CW, Kim CY. Combination therapy of cilengitide with belotecan against experimental glioblastoma. Int J Cancer. 2013;133:749-756.

View Article Google Scholar

12. Wan W Guo N Pan D Yu C Weng Y Luo S Ding H Xu Y Wang L Lang L Xie Q Yang M Chen X First experience of $18 \mathrm{~F}$-alfatide in lung cancer patients using a new lyophilized kit for rapid radiofluorination J Nucl Med 2013546916983683452 10.2967/jnumed.112.113563

13. Reynolds AR, Hart IR, Watson AR, Welti JC, Silva RG, Robinson SD, Da Violante G, Gourlaouen M, Salih M, Jones MC, Jones DT, Saunders G, Kostourou V, Perron-Sierra F,JC, Tucker GC, Hodivala-Dilke KM.

Stimulation of tumor growth and angiogenesis by low concentrations of RGD-mimetic integrin inhibitors. Nat Med. 2009;15:392-400.

View Article Google Scholar

14. Papo N Silverman AP Lahti JL Cochran JR Antagonistic VEGF variants engineered to simultaneously bind to and inhibit VEGFR2 and $\alpha_{v} \beta_{3}$ integrin Proc Natl Acad Sci U S A 201110814067 $14072316155210.1073 /$ pnas.1016635108

15. Ressurreiçao ASM, Vidu A, Civera M, Belvisi L, Potenza D, Manzoni L, Ongeri S, Gennari C, Piarulli U. Cyclic RGD-peptidomimetics containing bifunctional diketopiperazine scaffolds as new potent integrin ligands. Chem Eur J. 2009;15:12184-12188.

View Article Google Scholar

16. Marchini M, Mingozzi M, Colombo R, Guzzetti I, Belvisi L, Vasile F, Potenza D, Piarulli U, Arosio D, Gennari C. Cyclic RGD-peptidomimetics containing bifunctional diketopiperazine scaffolds as new potent integrin ligands. Chem Eur J. 2012;18:6195-6207.

View Article Google Scholar

17. Shiojima I, Walsh K. Role of Akt signaling in vascular homeostasis and angiogenesis. Circ Res. 2002;90:1243-1250.

View Article Google Scholar

18. Russo MA, Paolillo M, Sanchez-Hernandes Y, Curti D, Ciusani E, Serra M, Colombo L, Schinelli S. A smallmolecule RDG-integrin antagonist inhibits cell adhesion, cell migration and induces anoikis in glioblastoma cells. International J of Oncology. 2013;42:83-92.

View Article Google Scholar

19. Xu Y, Zhou Y, Lin H, Hu H, Wang Y, Xu G. Toll-like receptor 2 in promoting angiogenesis after acute ischemic injury. Int J Mol Med Mar. 2013;31:555-560.

View Article Google Scholar

20. Hynes RO. Cell-matrix adhesion in vascular development. J Thromb Haemost. 2007;1:32-40.

View Article Google Scholar

21. Kumar CC. Integrin alpha v beta 3 as a therapeutic target for blocking tumor-induced angiogenesis. Curr Drug Targets. 2003;4:123-131. 
22. Baranska P, Jerczynska H, Pawlowska Z, Koziolkiewicz W, Cierniewski CS. Expression of integrins and adhesive properties of human endothelial cell line EA.hy 926. Cancer Genomics Proteomics. 2005;2:265270.

View Article Google Scholar

23. Lomonaco SL Finniss S Xiang CL Lee HK Jiang W Lemke N Rempel SA Mikkelsen T Brodie C Cilengitide induces autophagy-mediated cell death in glioma cells Neuro Oncol 201113857 8653145473 10.1093/neuonc/nor073

24. Moreno PR, Purushothaman M, Purushothaman KR. Plaque neovascularization: defense mechanisms, betrayal, or a war in progress. Ann NY Acad Sci. 2012;1254:7-17.

View Article Google Scholar

25. Colombo R, Mingozzi M, Belvisi L, Arosio D, Piarulli U, Carenini N, Perego P, Zaffaroni N, De Cesare M, Castiglioni V, Scanziani E, Gennari C. Synthesis and biological evaluation (in vitro and in vivo) of cyclic arginine-glycine-aspartate (RGD) peptidomimetic-paclitaxel conjugates targeting integrin $\alpha \beta$. J Med Chem. 2012;55:10460-10474.

View Article Google Scholar

26. Eliceiri BP. Integrin and growth factor receptor crosstalk. Circ Res. 2001;89:1104-1110.

View Article Google Scholar

27. Shabbir SH, Eisenberg JL, Mrksich M. An Inhibitor of a Cell Adhesion Receptor Stimulates Cell Migration. Angew Chem Int Ed. 2010;49:7706-7709.

View Article Google Scholar

28. Waugh DJJ, Wilson C. The interleukin-8 pathway in cancer. Clin Cancer Res. 2008;14:6735-6741.

View Article Google Scholar

29. Brooks AN, Kilgour E, Smith PD. Molecular pathways: fibroblast growth factor signaling: a new therapeutic opportunity in cancer. Clin Cancer Res. 2012;18:1855-1862.

View Article Google Scholar

30. Paesler J, Gehrke I, Poll-Wolbeck SJ, Kreuzer KA. Targeting the vascular endothelial growth factor in hematologic malignancies. Eur J Haematol. 2012;89:373-384.

View Article Google Scholar

31. Hu B, Wei YQ, Tian L, Zhao X, Lu Y, Wu Y, Yao B, Liu JY, Niu T, Wen YJ, He QM, Su JM, Huang MJ, Lou YY, Luo Y, Kan B. Active antitumor immunity elicited by vaccine based on recombinant form of epidermal growth factor receptor. J Immunother. 2005;28:236-244.

View Article Google Scholar

32. Moulton KS, Karen S. Angiogenesis in atherosclerosis: gathering evidence beyond speculation. Curr Opin Lipidol. 2006;17:548-555.

View Article Google Scholar 